\title{
DE PRESSUPOSTOS SOBRE O CONHECIMENTO E A APRENDIZAGEM À PRÁXIS NA FORMAÇÃO DO TRADUTOR
}

\author{
FROM ASSUMPTIONS ABOUT KNOWING AND LEARNING TO PRAXIS IN \\ TRANSLATOR EDUCATION ${ }^{1}$
}

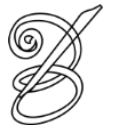 \\ Donald KIRALY2 \\ Professor-conferencista \\ Johannes Gutenberg University of Mainz \\ Germersheim, Rheinland-Pfalz, Alemanha \\ kiraly@uni-mainz.de \\ Traduzido por \\ Patrícia Rodrigues COSTA ${ }^{3}$ \\ Doutoranda em Estudos da Tradução (Bolsista CAPES - DS) \\ Universidade Federal de Santa Catarina \\ Florianópolis, Santa Catarina, Brasil \\ prcosta1986@gmail.com
}

Resumo: Este artigo discute o problema da ausência de programas acadêmicos de qualificação para professores de tradução que têm de recorrer às suas próprias intuições e à abordagem pedagógica popular. Objetiva identificar os entendimentos subjacentes da natureza do conhecimento e da aprendizagem que estão por trás da tradicional prática de ensino do "Quem quer vai fazer a primeira sentença?", bem como das abordagens didáticas alternativas. Embora existam algumas publicações inspiradoras e motivadoras sobre metodologias inovadoras de ensino centradas no aluno, estas ainda carecem de discussões sobre a epistemologia pedagógica ou quaisquer princípios gerais ou teoria da educação. A principal tese proposta neste artigo é que, a fim de seguir em frente, docentes de Tradução precisam estabelecer um diálogo mais amplo com a área da teoria e da práxis educacional, tendo na epistemologia da educação um ponto de partida imprescindível para este diálogo. De modo a preparar o cenário para esse diálogo, este artigo oferece um breve resumo de três grandes tendências epistemológicas: o empirismoracionalismo, o construtivismo e o emergentismo.

Palavras-chave: Construtivismo. Emergentismo. Empirismo-racionalismo. Abordagem pedagógica popular. Epistemologia pedagógica.

Abstract: The article discusses the problem of the absence of qualifying academic programmes for translation teachers who have to resort to their own intuitions and to a so-called folk pedagogical approach. It aims at identifying the underlying understandings of the nature of knowledge and learning that are behind the traditional 'Who will take the first sentence?' teaching practice as well as alternative didactic approaches. While there are some motivating and inspiring publications on innovative learner-centred teaching methodologies, they still lack any discussion of pedagogical epistemology or any general educational principles or theory. The main thesis proposed in the article is that in order to move forward, translation educators need to establish a dialogue with the broader domain of educational theory and praxis, with educational epistemology being a sensible starting point for this dialogue. To set the stage for such a dialogue, the article offers a brief overview of three major epistemological trends: empirico-rationalism, constructivism, and emergentism.

Keywords: Constructivism. Emergentism. Empiric-rationalism. Folk pedagogical approach. Pedagogical epistemology. 


\section{Da epistemologia do senso comum à práxis educacional com base em princípios}

$\mathrm{E}$ m 2008, Álvaro Echeverri publicou, como o título de seu artigo indica, a "enésima" reiteração das convocações das últimas décadas à uma mudança da prática convencional instrucionista centrada no professor em sala de aula na formação de

Este é um enésimo apelo, pois não é a primeira e certamente não será a última vez que nos inquietamos do fato de que as fórmulas pedagógicas escolhidas pelos formadores de tradutores, no que concerne às interações nos cursos de prática de tradução, em particular, não mudaram muito no decorrer das últimas cinco décadas. ${ }^{4,5}$ (ECHEVERRI, 2008, p. 67).

O presente ensaio poderia ser considerado um $n+1$ no que diz respeito ao artigo de autoria de Echeverri. Por estar envolvido numa jornada que visa contribuir com o aperfeiçoamento na formação de tradutores nos últimos trinta anos, tenho tido várias oportunidades por meio de publicações, de oficinas e de apresentações em conferências de revisitar a prática instrucional convencional na prática de tradução de sala de aula em meio ao contexto de ensino e de aprendizagem que, na formação de tradutores, permanece fora da zona de conforto do que eu chamo a comunidade de pensamento e práxis na área da educação ${ }^{6}$. Enquanto, por exemplo, professores escolares de matemática, ciências, religião, história e línguas são treinados, em todo mundo, por meio de programas acadêmicos que enfocam a teoria e a prática do ensino e da aprendizagem juntamente com seu respectivo assunto, a formação do tradutor continua na periferia da disciplina geral da educação. E, é ainda extremamente dependente das intuições dos professores sobre o que significa conhecer e a aprender, ou como denominado por Jerome Bruner (2006) por "pedagogia popular" e descrito por Bereiter e Scardamaglia (1993, p. 188) como "epistemologia do senso comum".

Claro, diversos campos do estudo na educação superior sofrem de um déficit pedagógico (ou atualmente, andragógico ${ }^{7}$ ) no sentido que catedráticos e professores universitários geralmente não tem treinamento especial ou formação na arte de ensinar (ou de facilitar a aprendizagem - o que alguns de nós acreditamos ser um complemento ou alternativa viável e digna do ensino em si).

Embora certamente ninguém conteste a loucura de ter um químico, um médico, um matemático, um engenheiro, um farmacêutico, um dentista, um psicólogo ou um antropólogo basear-se apenas no senso comum ou conhecimento popular da química, da medicina, da 
matemática, da engenharia, etc. como a base conceitual de suas atividades professionais, se espera que os professores universitários façam exatamente isso. Participamos do desenvolvimento curricular, criamos atividades, desenvolvemos e implementamos abordagens para promover a aquisição de conhecimento essencialmente com base em nossa experiência profissional prévia como mediadores linguísticos - e geralmente, nossa própria experiência prévia. Na ausência de programas de formação para professores de tradução, esse fórum acadêmico fundamental carece de discussão aprofundada sobre a epistemologia pedagógica, práticas de sala de aula ou testes de procedimentos entre a comunidade de formadores de tradutores. Sem um verdadeiro campo de "formação do tradutor", afirmo que, não pode haver praticamente nenhuma identificação de princípios comuns, somente trabalho colaborativo mínimo acerca de abordagens baseadas em princípios, e não há avaliação contínua e sistemática das práticas de ensino. É verdade que apresentações em conferências, oficinas, artigos em periódicos e outras publicações geram reflexões consideráveis para a comunidade de formadores de tradutores, mas a criação de programas acadêmicos qualificados destinados aos professores de Tradução é ainda um grande anseio.

Apesar de ou talvez por causa da falta de formação de docentes de tradução, estou certo que a maioria dos professores de tradução, bem como (ex)estudantes de tradução, estarão familiarizados com a abordagem convencional que Echeverri passou a criticar neste artigo e que Christiane Nord (1996) discutiu longamente em seu artigo tão apropriadamente intitulado: “"Wer nimmt denn mal den ersten Satz?” (algo como, Quem vai fazer a primeira sentença?). A abordagem pedagógica popular que ambos acadêmicos criticaram implica em ter estudantes tentando acumular conhecimento de procedimentos, técnicas e estratégias tradutórias corretas conforme os comentários intuitivos e as correções realizadas pelo professor ostensivamente mais conhecedor das traduções defeituosas e cheia de erros dos estudantes. O professor é visto claramente como uma autoridade na sala de aula (em termos de poder, e presumidamente também em termos de expertise) e geralmente ministra aulas usando a abordagem do "cuspe e giz”, sentando em frente a fileiras de estudantes, solicitando contribuições verbais individuais de participantes que leem suas respectivas traduções de partes do texto escolhido pelo professor.

Minha própria experiência com essa abordagem data de 1983, quando fui introduzido à formação de tradutores na School of Applied Linguistics and Cultural Studies (FTSK) na Universidade de Mainz, em Germersheim, Alemanha. O professor perguntava se outros estudantes tinham comentários a fazer e então providenciava seu próprio comentário acerca das soluções propostas. Isto persistia aula após aula, do primeiro semestre até o último semestre de 
um programa de estudos de quatro anos, o Diplom (mestrado). Era a abordagem onipresente para todas as línguas ensinadas na FTSK, e na formação de tradutores tanto de quanto para as línguas maternas dos estudantes. Observar as aulas foi o único tipo de formação ou treinamento disponível, que chegou ao meu conhecimento, para mim ou para qualquer outro instrutor naquele tempo. Àquela época, assim como atualmente, não existiam programas a nível universitário para a formação de instrutores de tradução e, à época, ao meu saber, não havia a oferta de oficinas intensivas destinadas aos formadores de tradutores ${ }^{8}$. Um levantamento da literatura sobre a formação de tradutores ${ }^{9}$ em 1985-86 revelou que pouco tinha sido feito até então para desenvolver abordagens de ensino que iam além de tentativas para, de alguma forma, transmitir essencialmente o conhecimento dos tradutores aos estudantes. Havia claramente uma comunidade solta de práticas de ensino de tradução àquela época, mas ao meu ver, não havia teorias subjacentes sobre a aquisição da competência do tradutor, e também praticamente nenhuma pesquisa sobre a formação do tradutor - ao menos encontrei muito pouca evidência acerca disto na literatura sobre os Estudos da Tradução da época (KIRALY, 1995).

Atualmente, cerca de 30 anos depois, ainda é possível encontrar diversa práticas de 230 ensino de tradução e não somente na FTSK - onde o professor se senta em frente de 20 a 60 estudantes posicionados em fileiras. Estes alunos ainda recebem um texto escolhido pelo professor e espera-se que os alunos o traduzam em casa por conta própria. A principal atividade pedagógica destas aulas é ainda ler em voz alta a sentença ou uma breve passagem dos rascunhos dos estudantes, para, em seguida, ser criticada, principalmente pelo professor. A atividade é desprovida das particularidades da autenticidade da tarefa que fazem da tradução profissional um processo de resolução de problemas de tradução reais incorporados num contexto holístico, multidimensional. Este contexto inclui as expectativas dos concorrentes, as demandas e os padrões, a interdependência entre uma miríade de atores em situações interlinguais e comunicações interculturais autênticas, e, por último, mas não menos importante, o objetivo de criar um produto de alta qualidade em termos de padrões impostos por um cliente.

Como já discuti em pormenores (KIRALY 1995, 2000), a abordagem convencional referida por Echeverri e Nord está bem estabelecida nas instituições de formação de tradutores em muitos países (TOURY, 1974; LADMIRAL, 1977; HOUSE, 1980; RÖHL, 1983; ENNSCONNOLLY, 1986; GABRIAN, 1986). Enquanto uma crítica considerável tem se acumulado sobre esta prática de ensino de tradução, por exemplo por todos os autores acima referidos, especialmente pelo papel desmotivador e passivo que isso confere aos estudantes, o papel 
desempoderante e dominador que confere aos professores [refletido no termo pomposo proposto por Ladmiral: performance magistrale (LADMIRAL, 1977, p. 508)], e a total falta de enraizamento e de preparação para a atual práxis profissional de tradução. E ainda, enquanto esta prática instrucional tem sido difundida até recentemente, pouco tem sido escrito sobre onde esta técnica pedagógica especial surgiu e por que parece persistir como um esteio na formação de tradutores profissionais. Ninguém parece ter inventado isto especificamente para o uso em aulas práticas de tradução ou, ao menos, não parece haver qualquer estudioso da didática da tradução que orgulhosamente afirme ser criação sua. Então, há alguma evidência que a abordagem “Quem vai fazer a primeira sentença?" talvez ainda se fundamente na epistemologia popular e seja uma prática de segunda mão perpetuada pela tradição - e uma aparente falta de alternativas viáveis.

Este é o tópico que me proponho a abordar neste artigo: quais são os respectivos entendimentos subjacentes à natureza do conhecimento e da aprendizagem que fundamentam esta abordagem e quais abordagem didáticas alternativas estão emergindo para o 'ensino' de tradução? Eu me inspirei para realizar esta incursão exploratória na filosofia da educação por trás das abordagens de formação de tradutores pelo trabalho iluminador acerca da história do desenvolvimento curricular de William Doll (2002) e na história da epistemologia educacional de Brent Davis (2004), ambos se referiram à educação em geral, e não especificamente sobre os Estudos da Tradução. Eu também estava motivado a me aprofundar neste tema quando recentemente coeditei uma coletânea de volumes de artigos com colegas de vários departamentos de língua da School of Translation, Linguistics and Cultural Studies (FTSK) da Universidade de Mainz (HANSEN-SCHIRRA \& KIRALY, 2012) e outro volume de excelentes textos de conferência apresentados em um painel de debates sobre inovações na formação de tradutores em uma importante conferência dos Estudos da Tradução realizada em 2012 (KIRALY, HANSEN-SCHIRRA \& MAKSYMSKI, 2013). Embora estes dois volumes tenham uma gama de abordagens inovadoras e significativamente centradas no aprendiz, que vão muito além da prática convencional, uma característica impressionante em ambos é a ausência essencial de qualquer discussão sobre a epistemologia pedagógica, ou de fato, de quaisquer princípios ou terias educacionais em geral em qualquer um dos capítulos do livro com somente algumas poucas exceções.

Ecoando o apelo de Echeverri (2008), é a minha forte convicção que a fim de ter uma plataforma justificável para ir além do status quo das técnicas de ensino decadentes e assistemáticas na formação de tradutores, precisamos estabelecer um diálogo mais amplo com 
a comunidade da teoria e da prática educacional e considerar seus métodos, história, fracassos e sucessos enquanto trabalhamos para melhorar nossas próprias abordagens pedagógicas específicas para a tradução - na teoria e na prática. Sugiro que um ponto de partida adequado para esse diálogo possa ser a epistemologia educacional: os pressupostos ou crenças sobre o conhecimento e o "vir a saber" que guiam a prática educacional.

Ao passo que em publicações prévias eu já tenha olhado extensivamente para as bases epistemológicas da abordagem socioconstrutivista na formação de tradutores (KIRALY, 2000) e da abordagem pós-positivista emergentista (KIRALY, 2012a), gostaria de ter esta oportunidade para contrastar o que eu vejo como epistemologias educacionais alternativas, competitivas e, talvez, incomensuráveis, e as implicações que estas diferentes visões podem ter para a prática do ensino de tradução, seu passado, seu presente e seu futuro ${ }^{10}$.

$\mathrm{Eu}$ me concentrarei principalmente no papel fundamental da epistemologia empíricoracionalista pode ter tipo, sobretudo por força do hábito ou prevalência, em restringir a formação do tradutor especialmente a uma prática reducionista-transmissionista no passado, e em como uma visão de mundo emergentista poderia muito bem inaugurar uma mudança de 232 paradigma na formação de tradutores no século 21. Entre estas duas visões díspares encontramse vários construtivismos. Em termos do meu desenvolvimento pessoal em relação à filosofia educacional, a elucidação e a aplicação da abordagem socioconstrutivista para facilitar o desenvolvimento da competência do tradutor na virada do milênio foi um passo crucial para meu próprio desenvolvimento como professor de tradução para além de um ensino convencional transmissionista e no sentido de facilitar o empoderamento do aprendiz. Porém, acho que minha abordagem socioconstrutivista já foi substituída, o que eu suspeitava ser inevitável desde o início devido à natureza evolutiva da construção da teoria de uma perspectiva pós-positivista. Como as profissões de mediação linguística continuam a evoluir, à medida que novas tecnologias fazem seu caminho inevitavelmente na rotina do tradutor, e como os paradigmas para a compreensão humana muda ao longo do tempo em termos de ontologia, de epistemologia e de cosmologia, então sempre haverá a necessidade contínua de se repensar e de se remodelar nossas teorias e práticas educacionais. No entanto, vejo a evolução do meu próprio pensamento para além do socioconstrutivismo como uma reinterpretação ao invés de uma rejeição. 


\section{O que a epistemologia tem a ver com isto?}

Esta seção lança um olhar nas três principais tendências epistemológicas, que, como sugerido por Doll (2002) e Davis (2004), podem ser rastreadas na história intelectual até praticamente os antigos gregos: 1) empirismo-racionalismo, 2) construtivismo e 3) emergentismo $^{11}$. Naturalmente, só me referirei a alguns pensadores que possam ser associados à estas tendências, e deve-se considerar que a caracterização destes indivíduos como pertencentes a um ou grupo de pensadores é dificilmente permanente. Meu objetivo é ilustrar minha própria interpretação das tendências epistemológicas e conscientizar os formadores de tradutores acerca destas tendências em vez de pintar um quadro compreensível e definitivo sobre eles.

\subsection{Empirismo-racionalismo: o possível pilar da pedagogia popular}

Uso o termo empirismo-racionalismo para me referir ao positivismo, uma visão do mundo modernista que data às escritas dos filósofos e dos cientistas do Iluminismo. Fundamenta-se nos pensamentos de dois grupos distintos de pensadores: de um lado, empiristas como Francis Bacon, John Locke, George Berkeley, David Hume, Galileu Galilei e Isaac Newton, e de outro lado, racionalistas como Réné Descartes, Gottfried Leibniz, Baruch Spinoza e Auguste Comte (o fundador do positivismo). Embora ambos os grupos de pensadores buscassem conhecer a verdadeira natureza do mundo ao redor deles, eles conduziram sua busca pela verdade universal e estável em duas direções distintas. Os empiristas acreditam que uma observação cuidadosa (e medida) das particularidades do mundo poderiam permitir à mente humana perspicaz encontrar a verdade sobre isto (uma abordagem de baixo para cima para assegurar a verdade), enquanto que os racionalistas acreditavam que é por meio de um raciocínio cuidadoso e lógico que poderíamos vir a conhecer a verdade objetiva sobre o mundo (uma abordagem de cima para baixo). Ainda que os métodos de busca da verdade para os empiristas e racionalistas pudessem divergir, ambos acreditavam que o conhecimento é prédefinido e pode ser descoberto se procurado com os meios e as ferramentas corretas. Em qualquer caso, de uma perspectiva positivista, ao passo que a verdade pode ser encontrada ao se examinar o mundo diretamente e/ou pela razão, o processo de ensino-aprendizagem pode ser entendido essencialmente como uma transmissão do conhecimento pretendido - independente de como o conhecimento foi adquirido originalmente pelo educador. Professores devem ser vistos como detentores do conhecimento que podem passar aos seus estudantes. Este tipo de atividade pedagógica pode, é claro, ser observada em aulas de muitas áreas ao redor do mundo 
em todos os níveis de educação. E, acredito que é esta tradição epistemológica de duas vertentes que foi uma importante fonte para a pedagogia popular que ainda prevalece nas aulas de prática de tradução.

Os argumentos dos filósofos e dos cientistas iluministas reconhecidos mundialmente foram sustentados pelos escritos de inúmeros pensadores anteriores e posteriores a eles. De fato, pode-se considerar que tanto o empirismo quanto o racionalismo na filosofia e na ciência têm raízes que remontam, ao menos, da Grécia Antiga. Sócrates, Euclides e Platão são geralmente vistos como racionalistas, enquanto que os Sofistas atomistas como Epicuro e Demócrito podem ser considerados os primeiros empiristas ${ }^{12}$. Um século antes de Descartes surgir, o pedagogo menos famoso, mas ainda muito influente, o filósofo francês e mestre das artes renascentistas Petrus Ramus inventou o conceito de "método", desenvolvido por ele no âmbito de seu trabalho pedagógico (DOLL, 2008, p.182; TRICHE, 2004). Francês do século XVI, Ramus escreveu um tratado sobre o método elucidando o que ele acreditava ser a estrutura ideal para o ensino dos clássicos e para passar o conhecimento de uma geração para a próxima. As ideias de Ramus sobre a implementação de um rígido currículo e a elaboração de planos de 234 aulas rigorosos espalharam-se rapidamente de país para país e foram transmitidas de geração para geração. Elas impactaram o próprio Descartes e gradualmente progrediram ao longo dos séculos para salas de aulas modernas ao redor do mundo por meio de obras de figuras influentes como Frederick Taylor nos Estados Unidos no começo do século XX. Taylor tornou-se famoso por melhorar os processos de fabricação de modo a garantir que a maior produtividade possível pudesse ser obtida de cada trabalhador da indústria. Enquanto as ideias de Taylor eram frequentemente condenadas no campo da gestão industrial por seus efeitos desumanos sobre o trabalhador, elas foram aclamadas pelos educadores como uma dádiva para aprimorar a educação, e foram adotadas em círculos educacionais e aplicadas a um currículo após o outro em todo os Estados Unidos e em diversos outros países. A lógica positivista e reducionista desenvolvida pelo behaviorista americano, especialista em currículos, Ralph Tyler na primeira metade do século XX, e que se inspirava amplamente no Taylorismo e na teoria estímuloresposta de Burrhus Frederic Skinner, só foi desacreditava na área educacional na década de 1990. E, de fato, ela continua a desempenhar um importante papel no desenvolvimento curricular e na prática pedagógica ainda hoje (DOLL, 2008, p.182; PINAR, 2008, p.491). Apesar de ter caído em descrédito como base para uma gestão efetiva décadas atrás, o Taylorismo ainda persevera na pedagogia popular e tem sido citada como um fator-chave para os males que afligem a educação nos Estados Unidos, por exemplo, no que diz respeito à ênfase 
extremamente excessiva nos testes padronizados e na obsessão com a responsabilidade do professor (ROSKELLY, 2009, p. 201).

Uma importante particularidade da epistemologia empírico-racionalista é que esta é fundamentada no Cartesianismo, na compreensão mecânica do mundo e na visão representacional do conhecimento da mente (ambas visões estão perdendo rapidamente seu brilho à medida que caminhamos inevitavelmente para a era pós-positivista). A partir desta perspectiva agora ultrapassada, tal como representada por empiristas como Bacon e Newton, o mundo funciona de forma parecida a um relógio: de uma forma complicada e mecânica (MORÇÖL, 2008, p. 107). Tanto o mundo físico quanto o mundo mental podem ser vistos a partir desta perspectiva, funcionando essencialmente da mesma maneira. O conhecimento é considerado palpável, capaz de ser armazenado na mente (e dentro do cérebro) e também é apropriado que este seja separado das experiências pessoais e repassados de modo proposicional para outros indivíduos - por exemplo do professor para o aprendiz. É por meio do pensamento Taylorista, fundamentado nos ideais de Ramus, que sua epistemologia é aplicada concretamente à prática de sala de aula:

A maioria dos procedimentos pedagógicos atuais... requer que a aprendizagem em sala de aula seja dividida em tarefas simples e organizadas metodologicamente na sequência correta de etapas para treinar os estudantes em um conhecimento, em habilidades e em um temperamento predeterminados burocraticamente ${ }^{13}$. (TRICHE e MCKNIGHT, 2004, 39)

Essa visão transmissionista da aprendizagem subjaz o papel de "instrutor" na sala de aula - o entendimento que o professor deve realmente possuir, de um certo modo, o conhecimento que deve ser adquirido pelos estudantes, e que deve ser capaz de lhes transmitir de modo eficiente e eficaz. A partir desta perspectiva, a discussão interativa em sala de aula, que é entendida somente como uma perturbação na distribuição eficiente de conhecimento de um cérebro para o outro, é uma oportunidade para praticar habilidades pré-definidas e consolidar conhecimentos canônicos e práticos adquiridos diretamente do processo ou de outras fontes especializadas. A discussão entre os estudantes nesta abordagem é desnecessária e talvez até prejudicial. $\mathrm{O}$ verdadeiro conhecimento sobre o mundo por ser identificado, empacotado, transmitido, ingerido, acumulado e testado.

Não é claro se o professor de tradução, em pé em frente a uma aula caracterizada pela abordagem “Quem vai fazer a primeira sentença?”, está realmente ciente da história e da tradição, por mim descrita, relacionadas a uma decisão inconsciente de educar futuros 
profissionais desta maneira. E, ainda assim, esta abordagem tem se perpetuado em diversos subcampos da educação na qual a abordagem convencional do "cuspe e giz", uma instrução centrada no professor, é fundamentada na epistemologia objetivista ou positivista que vê as fontes e o lugar do conhecimento em uma maneira "realista" (conhecimento entendido como um verdadeiro reflexo do mundo objetivamente real e diretamente perceptível) (DOLL, 1993; DAVIS e SUMARA 1997).

Para reiterar, a partir desta perspectiva 1) o conhecimento é encontrado na mente do indivíduo (particularmente na mente do professor em ambiente educacional), e 2) representa a verdade objetiva sobre o mundo que é passível de descobertas por meio da razão e/ou por meio da observação da realidade. Há também um entendimento tácito de que a experiência profissional do professor pode ter contribuído para o seu conhecimento. Mas, uma característica por excelência deste tipo de pedagogia popular é que o expertise do professor pode ser reduzido a axiomas, princípios, diretrizes, regras e, quiçá, a dicas e truques - de qualquer modo "palavras de sabedoria" podem ser entendidas como um modo de conduta pelos aprendizes e incorporadas à caixa preta de suas mentes, localizadas, por sua vez, em seus cérebros.

236 A partir desta perspectiva, a experiência real dos estudantes de tradução em lidar com atividades autênticas e situadas do tradutor poderia ser insignificante para o processo de aprendizagem - ao menos durante as aulas. A experiência autêntica poderia, é claro, ainda ser considerada uma importante parte das atividades de aprendizagem dos estudantes fora da sala de aula, por exemplo, em um estágio profissional ou uma vez que comecem a atuar profissionalmente. Mas, durante o curso em si, o que importa é a habilidade que o estudante detém de recuperar e integrar cognitivamente as verdades transmitidas pelo professor. De uma perspectiva educacional positivista, os aprendizes não precisam experimentar o verdadeiro mundo bagunçado e complicado do profissional da tradução. É muito mais apropriado para os professores purificar, simplificar e transmitir conhecimentos e habilidades: o pilar, se não a própria essência e a razão de ser da educação institucionalizada moderna.

É interessante notar que o "método" que Nord (1996) propõe para superar a pedagogia popular, subjacente à abordagem "Quem vai fazer a primeira sentença?”, é totalmente compatível às abordagens pedagógicas de Ramus, Taylor e Tyler. Ela propõe identificar subdomínios específicos da competência-alvo do tradutor e especificar o conteúdo preciso que deve ser ensinado para construir a competência tradutória global. Nord sugere usar a abordagem socrática de modo a permitir a interação em sala de aula (fundamentada na visão socrática racionalista de que a verdade poderia ser conhecida pelo professor e deduzida pelos estudantes 
por meio da lógica e com a orientação do professor). Acredito que método de Nord de fato representa um passo além do senso comum, da abordagem de ensino a-teórica para uma pedagogia educacional real, que reconhece sua epistemologia subjacente e constrói um conjunto de princípios coerentes e lógicos que pode ser discutido e avaliado pela comunidade de formadores de tradutores. E, por ser um método em desacordo tanto com a abordagem socioconstrutivista e emergentista para facilitar a aprendizagem, representa um modelo fundamentado epistemologicamente no instrucionismo ${ }^{14}$ que pode muito bem se adequar a alguns professores, alunos e situações de aprendizagem. O que é importante, para mim, não é ter uma epistemologia específica ou tentar promover a aprendizagem de uma maneira peculiar, mas criar e aplicar abordagens pedagógicas coerentes e com base em princípios que podem ser demonstradas como ferramentas viáveis na prática educacional.

Alguns professores, como eu, certamente acreditam que suas crenças pessoais sobre a natureza do conhecimento e da aprendizagem os guiam para além da abordagem didática reducionista de Ramus como proposta por Nord.

\subsection{Socioconstrutivismo: além do instrucionismo e do construtivismo radical}

Antes de sintetizar os princípios epistemológicos subjacentes ao construtivismo social, acredito ser importante reiterar algumas diferenças-chave entre o construtivismo radical de Piaget e o construtivismo social de Vygotsky. Enquanto aquele pode ser considerado como vinculado ainda à visão positivista, analiso que este está seguramente na esfera pós-positivista. Ambas teorias alegam que a aprendizagem se dá não pela ingestão da verdade descoberta empiricamente ou racionalmente, mas por meio da criação de entendimentos de mundo próprios. Para Piaget, isto estava diretamente relacionado ao processo de cognição individual (que, por sua vez, permite interação social), enquanto que para Vygotsky, é a interação social que antecede e conduz ao pensamento. Para Vygotsky, a aprendizagem é muito mais uma questão de construção (isto é, de interpretação) do mundo do que uma questão de construção de conhecimento sobre o mundo.

A teoria socioconstrutivista está intimamente ligada ao polímata russo Lev Vygotsky, o mundo é interpretado por indivíduos em e por meio de interação social ${ }^{15}$. A primeira perspectiva construtivista radical, que remonta à Grécia Antiga, tem sido atribuída ao sofista Protágoras no século V a.c. Protágoras é famoso devido a uma declaração segundo a qual: "O homem é a medida de todas as coisas", que tem sido interpretada como uma sugestão à visão filosófica relativista da relação do homem com o conhecimento. Durante o Iluminismo, Giambattista Vico 
(1668-1744), um filósofo político, retórico, historiadora e jurista, desenvolveu uma epistemologia que representou um claro contraste com o reducionismo. Em uma de suas obras principais, publicada em $1710^{16}$, Vico introduziu e defendeu seu famoso princípio verum factum (que afirma que somente o que é feito pode ser conhecido como verdade), que se fundamentou na visão de que o conhecimento deriva da criação ou invenção e não da observação.

As percepções vygotskianas acerca da aprendizagem, o papel mediador da cultura, os andaimes educacionais (scaffolding - o auxílio interativo para aprendizagem proporcionado por pessoas com maior conhecimento) e a zona de desenvolvimento proximal (ZPD) têm sido adotadas e adaptadas para aplicações educacionais em um grande número de esferas educacionais, incluindo matemática e ciência da educação. Um dos dois mais importantes pensadores associados à epistemologia socioconstrutivista, juntamente com Lev Vygotsky, é o filósofo, psicólogo e reformista educacional norteamericano John Dewey. Um dos três principais representantes da filosofia pragmática americana (junto de Charles Pierce e William James), Dewey rejeitava a "visão do espectador em relação ao conhecimento" e acreditava que 238 o conhecimento emerge por meio da ação. Enquanto Dewey acreditava firmemente na utilidade do método científico, compreendia o objetivo de sua aplicação não como uma descoberta da verdade sobre o mundo, mas como explicações viáveis que comunidades de pensamento e prática podem concordar em usar. Os aprendizes, segundo Dewey, precisam ser situados, se interessarem e se envolverem em atividades autênticas relevantes ao invés de serem recipientes passivos do conhecimento dos professores. A abordagem socioconstrutivista que propus para a formação do tradutor foi inspirada principalmente pelas obras de Vygotsky e Dewey e focouse nos pilares da autonomia do aprendiz, da aprendizagem cognitiva e do projeto de atividades colaborativas autêntico em sala de aula. A cognição ativa e interpessoal em um ambiente de ensino autêntico era o cerne desta visão socioconstrutivista de ensino. Assim como Dennis Sumara e Brent Davis afirmam

Para a [abordagem] construtivista [...] a cognição não é um processo de 'representação' de um mundo real que está “logo ali” esperando para ser aprendida, mas, sobretudo, é um processo de organizar e reorganizar seu próprio mundo de experiência subjetiva. (SUMARA e DAVIS, 1997, p. 409) ${ }^{17}$

Sumara e Davis identificam sucintamente o que a quintessência da mudança de paradigma implica no pensamento construtivista em geral: o abandono da crença mantida pelas 
tradições filosóficas racionalistas e empiristas de que a verdade objetiva pode ser encontrada "logo ali" no mundo e também transmitida ou consumida:

\begin{abstract}
... o construtivismo sugere que as ideias e as crenças [...] surgem por serem especialmente viáveis em um determinado contexto, não por serem ideais. Em termos de interação social, tais construções subjetivas precisam ser compatíveis somente com a construção dos outros, já que a viabilidade não é uma correspondência com alguns padrões determinados externamente, mas a manutenção de sua integridade em um determinado contexto ${ }^{18}$. (ibid)
\end{abstract}

Desta perspectiva, a aprendizagem é muito menos uma questão de aquisição ou absorção, e muito mais um processo situado de contextualização, de reconstrução do eu (um eu mais experiente, competente e autônomo). Enquanto tanto o construtivismo radical quanto o social enfatizam a necessidade de uma ação consubstanciada como o fundamento para a aprendizagem, o socioconstrutivismo adiciona o componente interpessoal primordial em conhecer e se tornar. Isto depende da interação autêntica e colaborativa como uma característica essencial de um ambiente de aprendizagem real.

Enquanto se preparam para introduzir seus leitores à teoria educacional pósconstrutivista, Sumara e Davis afirmam que um problema remanescente do construtivismo (radical) é que este ainda detém uma visão intrapessoal (para não dizer, intracraniana) da cognição:

... enquanto o construtivismo representa uma mudança significativa do cognitivismo e de outros modelos de representação da cognição, compartilha um princípio fundamental [...] o lugar da cognição é o indivíduo. (ibid) ${ }^{19}$

Embora o socioconstrutivismo considere que o sentido e o conhecimento são criados em interação com ambiente social do indivíduo e, portanto, surja a partir dos interstícios da interação interpessoal, no final, a mente do indivíduo ainda é o lugar onde o conhecimento é “construído" e armazenado. Além disso, a metáfora construção ainda enfatiza a objetivação do conhecimento e do entendimento de que os processos de trabalho são em grande parte mecânicos: simples ou complicados, na melhor das hipóteses. Como espero mostrar na seção final deste artigo, a etapa além do construtivismo em direção ao conhecimento emergente representa um avanço significante para além da visão de mundo mecanicista, positivista, reducionista que tem dominado a educação por séculos - rumo a uma abordagem que reconhece a natureza não-linear e imprevisível dos sistemas autênticos (não-reducionistas) de aprendizagem. 


\subsection{Do ensino e aquisição da aprendizagem rumo à aprendizagem emergente na era pós-positivista}

Além da sua contribuição para o pensamento socioconstrutivista, a obra de Dewey sobre metafísica também tem sido reconhecida como uma importante contribuição para a filosofia do processo, desenvolvida inicialmente no final do século XIX e defendida pelo renomado matemático e filósofo britânico Alfred North Whitehead (WHITEHEAD, 1950). Esta perspectiva filosófica compreende o mundo em termos evolutivos, como se estivesse em constante mudança - como Heráclito fez na Grécia Antiga, de acordo com o ditado a ele atribuído segundo o qual 'ninguém pode entrar duas vezes no mesmo rio' (KENNY 2010, p. 17). A filosofia do processo ressurge tardiamente no século $X X$ como ciência e pensamento complexos, que estão sendo pesquisados atualmente em uma variedade de áreas das ciências da natureza e social. Na seção final deste artigo, revisitarei a teoria da complexidade e o conceito de emergência que comecei a aplicar à formação do tradutor.

Esta seção, que devido às limitações espaciais, pode, na melhor das hipóteses, aguçar o interesse dos leitores que desejam mergulhar mais fundo nas opções pós-positivistas na

240 formação do tradutor. Tomei a liberdade de citar outros autores extensivamente de modo a introduzir os leitores a algumas das opiniões mais eloquentes nas áreas da filosofia da educação e da pesquisa pedagógica que contribuem para o diálogo com comunidades pós-positivistas da teoria e prática da educação em diversas áreas. Acredito que estas opiniões podem contribuir para uma base epistemológica viável para o crescente número de professores de tradução que se desiludiram com a prática do "cuspe e giz" na sala de aula e que se percebem atraídos pela pedagogia colaborativa, situada e orientada à prática. A primeira opinião é de Hanna Risku que, ao meu ver, é uma entre os poucos estudiosos dos Estudos da Tradução que se declarou abertamente em favor da adoção de uma epistemologia pós-positivista para promover a formação do tradutor.

Devido ao importante papel desempenhado pelo ambiente, qualquer tentativa de explicar a tradução por meio da descrição de processos mentais de um indivíduo sozinho está fadada ao fracasso. A mente é apenas uma parte da história. Precisamos descobrir não somente o que acontece na mente do tradutor, mas também o que acontece em outros lugares, por exemplo em suas mãos e seus computadores, em suas mesas, em suas línguas e em seus diálogos. A tradução não é feita exclusivamente pela mente, mas por sistemas complexos. Estes sistemas incluem as pessoas, os ambientes sociais e físicos específicos e todos os seus artefatos culturais (ênfase minha) (RISKU 2010, p. 103). 
Examinemos mais atentamente o que outros membros da comunidade da teoria e prática educacional pós-positivista têm a dizer acerca dos pontos levantados por Risku. Em primeiro lugar, a distinção entre sistemas complicados e complexos tem sido atribuída ao precoce cientista da computação Warren Weaver (1948). Segundo Weaver, sistemas complicados são mecânicos, assim como um relógio ou qualquer tipo de maquinário (ou mesmo um computador) e redutível aos seus componentes. Um técnico competente pode desmontar suas partes individualmente, repara-las, se necessário, e monta-las e estas funcionarão como funcionavam antes. Complexidade, entretanto, se refere a sistemas que têm um enorme número de componentes e não são redutíveis a essas partes; apresentam comportamento emergente (imprevisível, auto-organizável e autogerador), o que resulta em ser mais do que a soma de suas partes. Os exemplos primordiais de sistemas complexos são um formigueiro, qualquer organismo vivo e o cérebro. Sistemas complexos são dinâmicos e tendem a estar situados dentro de outros sistemas. Como exemplo, Brent Davis (professor de formação de matemáticos e um dos maiores especialistas sobre complexidade na educação) constatou que:

O cérebro [...] não é uma forma estática, mas um sistema dinâmico de mudanças que é fractalmente organizado: neurônios são aglomerados em minicolunas, minicolunas em macrocolunas, macrocolunas em áreas corticais, áreas corticais em hemisférios e em todos os níveis, agentes interagem entre si e afetam outros agentes. (DAVIS, 2004, p. 101 $)^{20}$

É em contextos envolvendo tais sistemas complexos que o reducionismo positivista organizado e os modelos de fluxograma euclidiano podem provar ter uma importância muito limitada. A natureza complexa dos sistemas complexos fractais (estrutura recorrente e infinitamente semelhante em todas as escalas) complementa a natureza do sistema complexo essencial da auto-organizaão ou "autopoiesis" (MATURANA e VARELA, 1980). É interessante notar que a geometria fractal, que tem sido usada para explicar uma enorme variedade de fenômenos naturais, só foi criada como um sistema matemático no final do século XX pelo matemático Benoît Mandelbrot (1983) (embora suas raízes remontem ao século XVII). A própria estrutura de um sistema complexo muda conforme sua interação com outros sistemas - isto é, uma vez que aprende. Ao aplicar estas características do sistema complexo aos processos de aprendizagem, Davis assevera:

Esta é uma das razões pelas quais a metáfora cognitivista do cérebro como computador é problemática. Cada episódio de aprendizagem implica em uma transformação física do cérebro, portanto, episódios subsequentes de aprendizagem são realizados por um cérebro diferente. Em nível biológico, a aprendizagem pessoal 
não é sobre aquisição, processamento ou armazenamento, mas sobre a estruturação emergente. (2004, p. 101) (Ênfases minhas) ${ }^{21}$

No contexto da filosofia educacional, a mentalidade pós-moderna nos encoraja a ver a cognição apenas como um sistema adaptativo emergente, que não envolve o conhecimento estático tanto quanto envolve o conhecimento dinâmico - constantemente mudando, iminentemente situado e incorporando o pensamento em ação:

O conhecimento é como um fractal: um evento contínuo e reiterativo pelo qual se entrelaça melhor sua história, sua situação imediata e seus projetos. Tal conhecimento jamais é fixo, nunca estável. (DAVIS e SUMARA, 2000, p. 831) ${ }^{22}$

Desta perspectiva, aprendizagem em salas de aula se torna uma questão radicalmente diferente da assimilação, geralmente passiva, de conhecimento predeterminado, suposta geralmente por uma epistemologia reducionista. A natureza da aprendizagem fractal, autossimilar, sugere que uma abordagem incorporada à prática de sala de aula também será refletida em um currículo menos artificialmente estruturado (para uma discussão mais detalhada

242 a esse respeito, ver KIRALY, 2012):

\begin{abstract}
A perspectiva pós-moderna do currículo respeita a confusão do todo e não tenta justificar e segmentar partes do todo em caixas fechadas. Neste quadro aberto, há espaço para jogar, correr riscos, e todo o tumulto inerente ao aprendizado. A aprendizagem nem sempre precisa seguir etapas sequenciais, pelo contrário é complexa e avança aos trancos e barrancos. O paradigma pós-moderno inclui exceções e não sente necessidade de encontrar a verdade suprema. (LEWIS, 2004, p. $121-122)^{23}$
\end{abstract}

William Doll resumiu a essência da sala de aula pós-moderna a partir de uma pedagogia convencional do cuspe e giz da seguinte maneira:

\begin{abstract}
A aprendizagem ocorre atualmente não por meio da transmissão direta de um especialista para um aprendiz ou de um professor para um estudante, mas de uma maneira não-linear em aula ao explorar uma situação/problema/questão em conjunto e certamente a partir de múltiplas perspectivas. (DOLL, 2008, p. 193) ${ }^{24}$
\end{abstract}

Isto nos traz de volta ao tipo de pedagogia colaborativa com base em projetos autênticos proposta por mim em A Social Constructivist Approach to Translator Education (KIRALY, 2000) que começou a se desenvolver no século XXI na formação do tradutor. As contribuições para a literatura sobre abordagens pós-instrucionistas para a formação de tradutores próximo à virada do milênio, nos Estudos da Tradução, por si só, eram limitadas aos trabalhos de 
Mackenzie e Nieminen (1997) e de Jean Vienne (1994). Estes autores não se fundamentaram abertamente em qualquer epistemologia, cosmologia ou teoria pedagógica específica, no entanto, serviram como uma importante fonte de inspiração para minha própria abordagem que se fundamentou nos princípios do socioconstrutivismo. A perspectiva teórica fornecida pela emergência produz um incentivo ainda mais poderoso para a realização de projetos de trabalho autêntico em sala de aula do que o produzido pelo socioconstrutivismo. As condições de trabalho quase autênticas que surgem do trabalho em um projeto real em sala de aula refletem a compreensão da cognição e da aprendizagem como ações congregadas ao invés do acréscimo de pedaços de conhecimento e habilidades. Segundo declarado por Risku:

\footnotetext{
Se a aprendizagem é situada e, ao invés de abstrata e descontextualizada, depende do contexto, a gestão de diferentes situações profissionais se torna o principal objetivo educacional... Por isso, é de extrema importância que professores de tradução e interpretação integrem tarefas autênticas ou quase autênticas ao seu ensino. (RISKU, 2010, p. 101 $)^{25}$
}

Uma visão emergentista não somente permite, mas exige que os professores desçam de seus pedestais de autoridade. Isto implica em uma mudança obrigatória em seus papéis de purificadores e transmissores de conhecimento a guias e companheiros no caminho dos alunos rumo à experiência. O plano de curso não é mais uma tarefa para ser realizada por um professor sozinho antes do início do curso, isto se torna um plano experimental que surge com novos desafios e rumos inesperados, e que conduz a metas imprevisíveis conforme o curso progride. Os objetivos de aprendizagem se tornam muito mais difícil de especificar, pois diferirão de estudante para estudante e, no melhor dos casos, evoluirão de uma maneira única para cada um dos estudantes ao longo de cada curso e ao longo de todo o programa de estudos. Assim, uma mudança em nossa epistemologia pedagógica subjacente, conforme nosso entendimento básico do que significa aprender a atuar como um profissional mediador das línguas, trará consigo uma pletora de novos desafios para os professores, os aprendizes e as nossas próprias instituições educacionais. Este, contudo, seria um pequeno preço a pagar por uma pedagogia que é muito mais adequada do que o cuspe e giz para o ainda emergente Zeitgeist ${ }^{26}$ pós-moderno.

\section{Conclusão}

Não foi minha intenção nesta curta pesquisa contar a história completa de algo, mas sim encorajar meus leitores, e, especialmente, aqueles que são ou pretendem se tornar formadores de tradutores, a investigar suas próprias epistemologias da prática pedagógica. Assim como é o 
caso dos estudantes de tradução, para quem sabemos que não se aprende a traduzir meramente traduzindo, do mesmo modo, professores de tradução não se tornam mestres simplesmente ensinando. A reflexão é também um componente vital desta equação. Espero ter demonstrado que ao olhar em retrospectiva o pensamento educacional por dezenas, centenas ou milhares de anos, podemos avaliar melhor que tipo de formadores somos, e que tipo gostaríamos de ser a fim de atender aos nossos estudantes, às instituições e à sociedade no futuro. A figura 1 apresenta somente alguns dos interlocutores que achei serem especialmente edificante ao longo de minha própria busca pessoal para melhor entender algumas das complexidades da aprendizagem e do ensino.

Figura 1. Perspectivas emergentes na epistemologia educacional
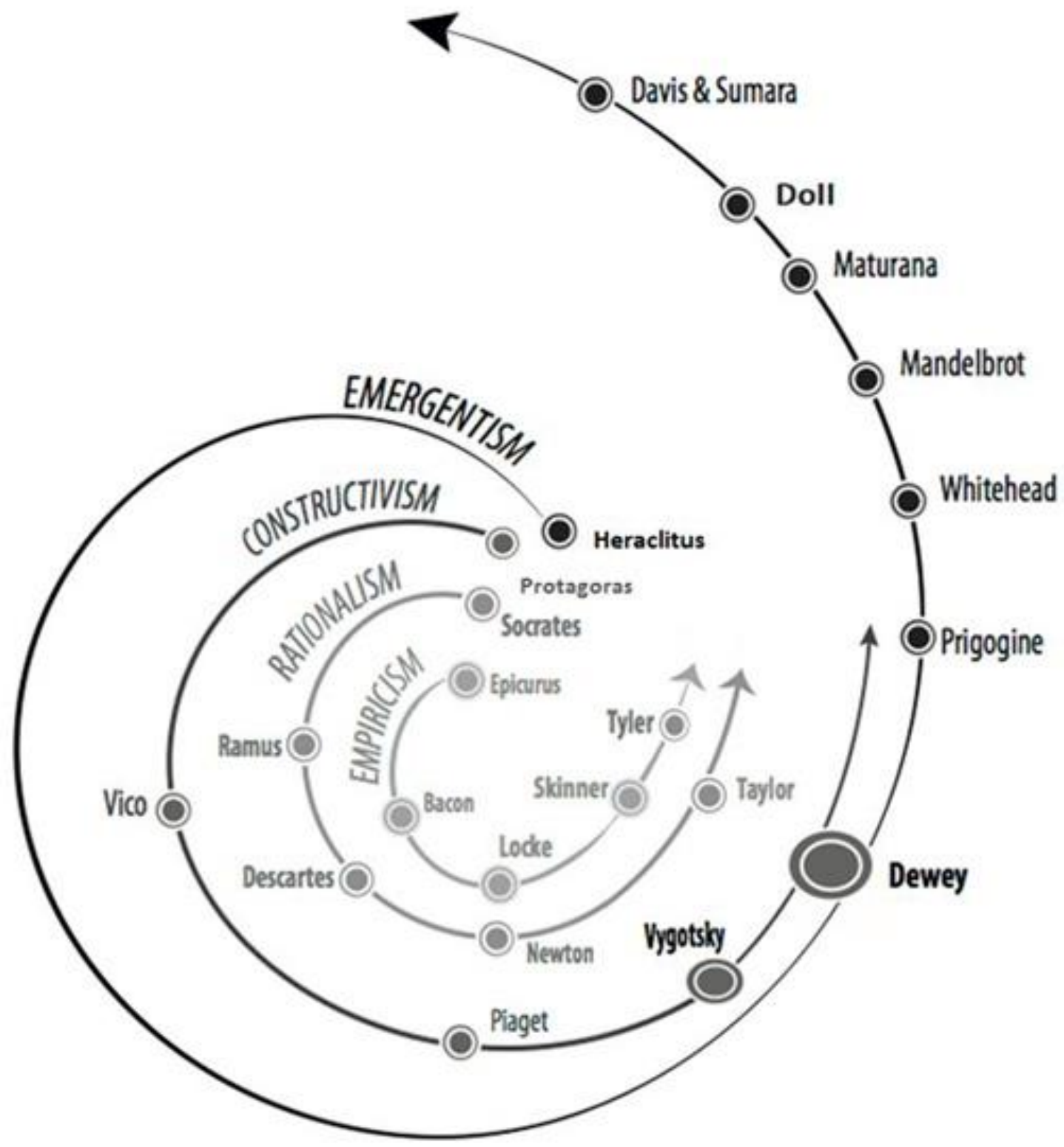


\section{REFERÊNCIAS BIBLIOGRÁFICAS}

BEREITER, Carl; SCARDAMAGLIA, Marlene. Surpassing Ourselves - An Inquiry into the Nature and Explications of Expertise. Chicago e Lasalle, Illinois: Open Court, 1993.

BRUNER, Jerome. In Search of Pedagogy Volume II. New York: Routledge, 2006.

DAVIS, Brent. Inventions of Teaching. Mahwah, EUA: L. Erlbaum Associates, 2004.

DAVIS, Brent; SUMARA, Dennis. Cognition, complexity, and teacher education. EUA: Harvard Educational Review, 1997, v. 67, n. 1, p.105-125.

Complexity Science and Education: Reconceptualizing the Teacher's Role in Learning. EUA: Interchange, 2007, v. 38, n. 1, p.53-67.

Complexity as a Theory of Education. Rio de Janeiro, Brasil: Transnational

Curriculum Inquiry, 2008, v. 5, n. $2 . \quad$ Disponível em: http://ojs.library.ubc.ca/index.php/tci/article/view/75/278. Acesso: 31 mar. 2016.

DOLL, William E. A Postmodern Perspective on Curriculum. New York: Teachers College Press, 1993.

Ghosts and the Curriculum. In: DOLL, William; GOUGH, Noel (eds.). Curriculum Visions. New York, Peter Lang, 2002.

Complexity and the Culture of Curriculum. In: MASON, Mark (ed.). Complexity Theory and the Philosophy of Education. Malden, Georgia, EUA: Wiley-Blackwell, 2008, p.181-203.

ECHEVERRI, Álvaro. Énième plaidoyer pour l'innovation dans les cours pratiques de Traduction. Préalables à L'innovation?. Montréal, Canadá: TTR: Traduction, Terminologie, Rédaction, 2008, v. 21, n. 1, p. 65-98. Disponível em: http://id.erudit.org/iderudit/029687ar. Acesso: 31 mar. 2016.

ENNS-CONNOLLY, Esther. Translation as an Interpretive Act: A Narrative Study of Translation in University Level Foreign Language Teaching. (Tese de doutorado). Toronto, Canadá: University of Toronto, 1986.

GABRIAN, Britta. Ziel oder Zeillosigkeit des Übersetzungsunterricht. Heidelberg, Alemanha: TextKontext, 1986, v.1, n.1, p. 48-62.

HANSEN-SCHIRRA, Silvia; KIRALY, Don (eds). Projekte und Projektionen in der translatorischen Kompetenzentwicklung. Frankfurt, Alemanha: Peter Lang, 2012

HOUSE, Juliane. Übersetzen im Fremdsprachenunterricht. IN: POULSEN, S. O.; WILSS, Wolfram (eds). Angewandte Übersetzungswissenschaft. Arhus, Dinamarca: Wirtschaftsuniversität Arhus, 1980, p. 7-17.

KENNY, Anthony. A New History of Western Philosophy: Oxford, Inglaterra: OUP, 2010. 
KIRALY, Don. Pathways to Translation: Pedagogy and Process. Kent, Ohio, EUA: Kent State University Press, 1995.

. A Social Constructivist Approach to Translator Education. Manchester, Inglaterra: St. Jerome, 2000.

. Growing a Project-Based Translation Pedagogy. Montréal, Canadá: Meta: journal des traducteurs / Meta: Translators' Journal, 2012a, v. 57, n.1, p. 82-95. Disponível em: http://www.erudit.org/revue/meta/2012/v57/n1/1012742ar.pdf. Acesso: 31 mar. 2016.

Skopos Theory Goes to Paris: Purposeful Translation and Emergent Translation Projects. Atenas, Grécia: MTM, 2012b, v.4, p. 119-144. Disponível em: http://www.mtmjournal.gr/datafiles/files/MTM_4.pdf. Acesso: 31 mar. 2016.

KIRALY, Don; HANSEN-SCHIRRA, Silvia; MAKSYMSKI, Karin (eds). New Prospects and Perspectivs for Educating Language Mediators. Tübingen, Alemanha: Narr Verlag, 2013.

LADMIRAL, Jean-Réné. La traduction dans le cadre de l'institution pédagogique. Alemanha: Die Neueren Sprachen, 1977, v.76, p. 489-516.

LEWIS, Nancy S. The Intersection of Postmodernity and Classroom Practice. Califórnia, EUA: Teacher Education Quarterly, 2004, p. 119-134.

MACKENZIE, Rosemary; NIEMINEN, Elina. Motivating students to achieve quality in translation. IN: KLAUDY, Kinga; KOHN, Janós (eds). Transferre Necesse Est. Budapeste, Hungria: Scholastica, 1997, p. 339-344.

MANDELBROT, Benoît B. The Fractal Geometry of Nature. New York, EUA: Henry Holt \& Company, 1983.

MATURANA, Umberto; VARELA, Francisco. Autopoiesis and Cognition: the Realization of the Living. Boston, EUA: D. Reidel Publishing Co., 1980.

MORÇÖL, Göktu. What is Complexity Science? Postmodernist or Postpositivist?. Cambridge, Massachusetts, EUA: Emergence: A Journal of Complexity Issues in Organizations and Management, 2001, v.3, n. 1, p. 104-119.

NORD, Christiane. Wer nimmt denn mal den ersten Satz? Überlegungen zu neuen Arbeitsformen im Übersetzungsunterricht. IN: GERZYMISCH-ARBOGAST, H.; HALLER, J.; STEINER, E. (eds). Übersetzungswissenschaft im Umbruch, Festschrift für Wolfram Wilss. Tübingen, Alemanha: Narr, 1996, p. 313-327.

PINAR, William. Curriculum theory since 1950: Crisis, reconceptualization, internationalization. IN: CONNELLY, F.; HE, M.; PHILLION, J. (eds). The SAGE Handbook of Curriculum and Instruction. Los Angeles, EUA: Sage Publications, 2008, p. 491-514.

RISKU, Hanna. Translatorische Kompetenz. Tübingen, Alemanha: Stauffenberg, 1998. 
A Cognitive Scientific View on Technical Communication and Translation. Do embodiment and situatedness really make a difference?. Amsterdam, Países Baixos: Target, 2010, v. 22, n. 1, p. 94-111.

RÖHL, Monika. Ansätze zu einer Didaktik des Übersetzens. (Dissertação de Mestrado). Mainz, Alemanha: Johannes Gutenberg-Universität Mainz, 1983.

ROSKELLY, Hephzibah. Teaching Like Weasels. IN: SHAPIRO, Sri (ed.). Education and Hope in Troubled Times, in Education and Hope in Troubled Times. London, Inglaterra: Routledge, 2009, p. 198-209.

SUMARA, Dennis; DAVIS, Brent. Enactivist Theory and Community Learning: toward a complexified understanding of action research. Abingdon, Inglaterra: Educational Action Research, 1997, v. 5, n. 3, p. 403-422. Disponível em: http://www.tandfonline.com/doi/pdf/10.1080/09650799700200037. Acesso: 31 mar. 2016.

TOURY, Gideon. The Notion of Native Translator and Translation Teaching. IN: WILSS; Wolfram; THOME, Gisela (eds). Die Theorie des Übersetzens und ihr Aufschlußwert für die Übersetzungs- und Dolmetschdidaktik. Tübingen, Alemanha: Gunter Narr, 1974, p. 186-95.

TRICHE, Stephen; MCKNIGHT, Douglas. The Quest for Method: the Legacy of Peter Ramus. Abingdon, Inglaterra: History of Education, 2004, v. 33, n. 1, p. 39-54.

TRUEIT, Donna. Pragmatism, Postmodernism, and Complexity Theory. New York, EUA. Londres, Inglaterra: Routledge, 2012.

VARBELOW, Sonja. Instruction, Curriculum and Society: Iterations Based on the Ideas of William Doll. Eskisehir, Turquia. International Journal of Instruction, 2012, v.5, n. 1, p.8794. Disponível em: http://www.e-iji.net/dosyalar/iji_2012_1_5.pdf. Acesso: 31 mar. 2016.

VIENNE, Jean. Toward a Pedagogy of Translation in Situation. Abingdon, Inglaterra: Perspectives, 1994, v. 1, p. 51-59.

WEAVER, Warren. Science and Complexity. Durham, EUA: American Scientist, 1948, v. 36, n. 4 , p. 536-544.

WHITEHEAD, Alfred North. The Aims of Education and Other Essays. Londres, Inglaterra: E. Benn, 1950.

\footnotetext{
${ }^{1}$ N.de.T.: A tradução deste artigo foi autorizada, via e-mail, pelo autor, Prof. Dr. Donald Kiraly, em 24 de agosto de 2015, e pelo Conselho Editorial do periódico inTRAlinea em 4 de setembro de 2015. Agradecemos imensamente a gentileza pelas autorizações para pudéssemos traduzir e publicar o artigo abaixo referenciado.

KIRALY, Donald. From Assumptions about Knowing and Learning to Praxis in Translator Education. Bologna, Itália: inTRAlinea, online translation journal, 2014. Disponível em: http://www.intralinea.org/specials/article/2100. Acesso: março 2016.

${ }^{2}$ Donald KIRALY - Doutor em Secondary Education com especialização em Second Language Acquisition and Teacher Education com tese de doutorado intitulada Toward a Systematic Approach to Translation Skills Instruction pela University of Illinois at Champaign Urbana (1990). Mestre emEnsino de Francês como Língua Estrangeira pela University of Illionois at Champaign-Urbana (1982) e em Relações Internacionais pela Florida State
} 
University (1977). Graduado em Ciência Política pela Cleveland State University (1976). Desde 1984 é professorconferencista na School of Translation, Interpreting, Linguistics and Cultural Studies (FTSK) na Johannes Gutenberg University of Mainz, Alemanha. Disponível em: http://www.fb06.uni-mainz.de/esue/52.php Acesso: março 2016.

${ }^{3}$ Patrícia Rodrigues COSTA - Doutoranda em Estudos da Tradução na Universidade Federal de Santa Catarina. Mestre em Estudos da Tradução pela Universidade de Brasília (2013). Engenheira Agrônoma (2014) e Bacharel em Letras - Tradução/Inglês (2008) pela Universidade de Brasília. Disponível em: http://lattes.cnpq.br/9546437584230118 Acesso: março 2016.

${ }^{4}$ Ceci est un énième plaidoyer, parce que ce n'est pas la première ni certainement la dernière fois que l'on s'inquiète du fait que les formules pédagogiques choisies par les formateurs de traducteurs, en ce qui concerne les interactions dans les cours pratiques de traduction, en particulier, n'ont pas beaucoup changé au cours des cinq dernières décennie (Echeverri 2008: 67).

${ }^{5}$ N.de.T.: Todas as citações deste artigo foram por nós traduzidas.

6 O conceito deriva do termo "comunidade de prática" cunhado por Jean Lave e Etienne Wenger. Uma "comunidade de teoria e práxis" enfatiza a natureza reflexiva do trabalho e da 'práxis' da comunidade, creio que maior clareza enfatiza a natureza consciente do trabalho em curso e evita a ambiguidade inerente do termo "prática" (com seu segundo conceito-chave de exercício repetitivo).

${ }^{7}$ N. de. T.: O termo andragógico deriva do termo "andragogia", cunhado por Malcolm S. Knowles, pai da andragogia moderna, na década de 1970 (MATAI, P; MATAI, S. 2009.). Enquanto a pedagogia “[...] deriva de uma expressão grega que se refere à educação da criança, às vezes considera-se a palavra como específica para a educação de crianças de jovens, usando-se o termo "andragogia", cunhado mais recentemente, para fazer referência à educação de adultos [...]" (UNESCO, 2013, p. 71). O termo "andragogia é mais usado em Portugal; no Brasil, usa-se educação de jovens e adultos (EJA)" (UNESCO, 2016, p. 71). Destacamos que neste artigo o termo andragógico refere-se à educação em nível superior.

MATAI, Patrícia Helena L. S; MATAI, Shigueharu. Cooperative Education: Angragogy. Orlando, EUA: The $2^{\text {nd }}$ 248 International Symposium on Academic Globalization: AG 2009. Disponível em: http://www.iiis.org/CDs2009/CD2009SCI/ag2009/PapersPdf/A064IQ.pdf Acesso: mar. 2016.

UNESCO. Glossário de Terminologia Curricular. Brasília: Setr de Educação da Representação da UNESCO no Brasil, 2016, 115p. Tradução: Rita Brossard. Disponível em: http://unesdoc.unesco.org/images/0022/002230/223059por.pdf. Acesso: mar. 2016.

${ }^{8}$ Worshops intensivos têm sido desde então implementados (por exemplo, os organizados e co-ministrados pelo autor) entre 1999 e 2006 no Monterey Institute of International Studies, Estados Unidos, e na Universitat Rovira $i$ Virgilli, Tarragona, Espanha, e na Universitat de Vic, Barcelona, Espanha. Há atualmente também um único mestrado em pedagogia da tradução criado recentemente na Macquarie University, Sydney, Austrália, mas mesmo esse programa tem sido ofertado de forma intermitente devido à falta de estudantes.

${ }^{9}$ Este estudo aprofundado acerca das abordagens de ensino na formação de tradutores foi a dissertação de autoria de Röhl defendida na FTSK em 1983, que se tornou um estímulo fundamental para a minha dissertação defendida na University of Illinois, EUA, em 1990 e intitulada "Toward a Systematic Approach to Translation Skills Intruction".

${ }^{10}$ Ao longo deste trabalho, o termo epistemologia será usado para se referir às "teorias do conhecimento e da aprendizagem" apensar que alguns pós-modernista possam compreender epistemologia em termos cartesianos como sendo como sabemos e vimos a saber o mundo objetivamente. Adoto o termo epistemologia educacional para enfatizar o uso de princípios educacionais de modo a fomentar a aprendizagem.

${ }^{11}$ Empirismo e racionalismo podem, é claro, ser descritos como epistemologias distintas, já que compreendem a verdade como sendo acessível de duas maneiras radicalmente diferentes: por meio dos sentidos e por meio do raciocínio, respectivamente. Porém, ambas visões compreendem a verdade como sendo detectável, identificável, acessível e recuperável; as consequências disto são as características comuns nas abordagens de ensino fundamentadas na visão empirista e na racionalista: o ensino centrado no professor.

12 A história do modernismo ocidental do ponto de vista educacional tem sido discutida longamente e exaustivamente nas obras de William Doll (TRUEIT, 2012). Não abordarei as relações entre o pensamento epistemológico ocidental e oriental neste artigo, mas farei nas próximas publicações.

${ }^{13}$ Most current pedagogical procedures... require classroom learning to be broken down into simple tasks and arranged methodologically into the right sequence of steps to train students in bureaucratically predetermined knowledge, skills and dispositions. (Triche and McKnight 2004: 39)

${ }^{14}$ O termo instrucionismo é atribuído a Seymour Papert (1993).

15 As limitações de espaço me impedem de revisar detalhadamente a perspectiva socioconstrutiva. O leitor deve consultar a obra A Social Constructivist Approach to Translator Education (KIRALY, 2000) para uma discussão aprofundada acerca da teoria socioconstrutivista e sua aplicação à formação do tradutor.

${ }^{16}$ N.de.T.: VICO, Giambattista. De antiquissimaitalorum sapientia ex linguae latinae originibus eruenda. 1710.

KIRALY. De pressupostos sobre o conhecimento e a aprendizagem à práxis na formação do tradutor Belas Infiéis, v. 5, n. 1, p. 227-249, 2016. 
${ }^{17}$ For the constructivist [...] cognition is not a process of 'representing' a real world that is 'out there' waiting to be apprehended but, rather, is a process of organising and re-organising one's own subjective world of experience. (Sumara and Davis 1997: 409)

18 ... constructivism suggests that ideas and beliefs [...] emerge because they are personally viable in a given context, not because they are ideal. In terms of social interaction, such subjective constructions need only be compatible with the constructions of others, for the measure of viability is not a match with some externally determined standard, but the maintenance of one's integrity in a given context. (ibid)

${ }^{19}$... while constructivism represents an important departure from cognitivism and other representational models of cognition, it shares one fundamental tenet [...] that the locus of cognition is the individual. (ibid)

${ }^{20}$ The brain [...] is not a static form, but a vibrantly changing system that is fractally organised: neurons are clustered into mini columns, mini columns into macro columns, macro columns into cortical areas, cortical areas into hemispheres - and at every level agents interact with and affect other agents. (Davis 2004: 101)

${ }^{21}$ This is one of the reasons that the cognitivist brain-as-computer metaphor is problematic. Each event of learning entails a physical transformation of the brain; hence subsequent events of learning are met by a different brain. On the biological level, personal learning is not about acquisition, processing or storing, but about emergent structuring. (2004: 101) (My emphasis)

${ }^{22}$ Knowing is fractal-like: a continuous, re-iterative event through which one knits together one's history, one's immediate situation, and one's projects. Such knowing is never fixed, never stable. (Davis \& Sumara 2000: 831)

${ }^{23}$ The postmodern perspective of curriculum respects the messiness of the whole and does not try to justify and segment parts of the whole into closed boxes. In this open framework, there is room for play, chance, and the turmoil inherent in learning. Learning does not always have to proceed in sequential steps, but is complex and moves in fits and starts. The postmodern paradigm embraces exceptions and does not feel a need to find the ultimate truth (Lewis 2004: 121-122).

${ }^{24}$ Learning now occurs, not through direct transmission from expert to novice, or from teacher to student, but in a non-linear manner in a class exploring a situation/problem/issue together, and indeed from multiple perspectives. (Doll 2008: 193)

${ }^{25}$ If learning is situated and context-dependent instead of abstract and decontextualised, the management of different professional situations becomes the primary educational objective.... Therefore it is of paramount importance that teachers of translation and interpreting integrate authentic or near-authentic translation tasks into their teaching. (Risku 2010: 101)

${ }^{26}$ N.de.T: Zeitgeist: Termo alemão utilizado para se referir ao espírito da época ou espírito do tempo.

RECEBIDO EM: 02 de maio de 2016 ACEITO EM: 07 de junho de 2016 